\title{
Optimal Combination of Flow Field Channels, Gas Diffusion Layers, and Catalyst Layers for Proton Exchange Membrane Fuel Cell
}

\author{
C. Y. Liu, L. H. Hu, and C. C. Sung
}

\begin{abstract}
This study presents an optimal combination of flow field channels, gas diffusion layers, and catalyst layers for proton exchange membrane fuel cell to achieve the highest electrochemical performance. A flow field plate with serpentine and straight channels machined is used to assemble in the reference unit cell for the study. In the beginning, a result of randomly chosen four MEAs from twenty-five samples is shown to distinguish the systematic patterns from random variation. Four combinations of different areas of flow field channels, gas diffusion layers, and catalyst layers are tested further, and discussed the issues of the performance affection. Under the test condition of providing hydrogen and oxygen, the performance of the optimal combination is $1.07 \mathrm{~W} / \mathrm{cm}^{2}$, which is two times higher than that of the worst one $\left(0.51 \mathrm{~W} / \mathrm{cm}^{2}\right)$.
\end{abstract}

Index Terms - Catalyst layer, flow field channel, gas diffusion layer, fuel cell.

\section{INTRODUCTION}

Fuel cells are devices or systems which can convert the chemical energy of hydrogen and oxygen into electricity directly, and generate only heat and water [1]-[4]. With the advancement of technology and the rise of human environmental awareness, fuels cell have become one of the potential renewable energy, including solar cell, wind turbine energy, biomass, and so on. The theory and the reaction of fuel cells are quite simple and their reactants and products are environmental friendly. However, there are still many challenges which need to be overcome for the profit-making application. Half a century ago, proton exchange membrane fuel cell has been used as a power system in the space project.

Due to the high cost, fuel cells are not broadly applied in our daily life. In recent years, each component and material of fuel cells are technical breakthroughs and cost down. Fuel cells are being noticed and developed again. Fuel cells related products are gradually commercialized and can be purchased easily [5]-[7].

Among many types of fuel cells, proton exchange membrane fuel cell (PEMFC) is the most mature and well developed, such as for portable devices, small power generators, and transportations and so on. The key component of proton exchange membrane fuel cell, membrane electrode assembly (MEA), is called the heart of

Manuscript received October 31, 2012; revised January 10, 2013. This work was supported in part by National Science Council (NSC), R.O.C. Taiwan.

C. Y. Liu and C. C. Sung are with the Department of Engineering Science and Ocean Engineering, National Taiwan University, Taipei 10617 Taiwan (e-mail: d99525002@ntu.edu.tw, ccsung@ntu.edu.tw).

L. H. Hu is with the Institute of Atomic and Molecular Sciences, Academia Sinica, Taipei 10617 Taiwan (e-mail: lunghao.hu@gmail.com).
PEMFC. Many researches discuss how to reach the maximum performance by using the minimum resources to avoid wastes. Bayrakceken et al. [8] improved the resistance between the proton exchange membrane and catalyst layers. The current researches focusing on reducing the noble catalyst loading are widely developed to achieve the highest electrochemical performance [9]-[13].

In this study, we focus on the geometrical combinations from three layers. The final goal is to design an optimal PEMC and to obtain the highest performance with less fuel and volume waste.

\section{EXPERIMENTAL}

\section{A. Materials}

All materials were used in the study without any further treatment, as-received. Dupont Nafion ${ }^{\circledR}$ NRE212 $(50 \mu \mathrm{m})$ membranes and Nafion ${ }^{\circledast}$ solution - DE520 were purchased from Dupont Taiwan agent: Tension Energy Inc. Platinum, nominally $50 \%$, on carbon black ( $50 \mathrm{wt} \% \mathrm{Pt} / \mathrm{C}$ Johnson Matthey HiSpec ${ }^{\mathrm{TM}}$ ) purchased from Alfa-Aesar was mixed in Nafion solution to form the. One type of commercial GDL was used in the study, Sigracet SGL 10BC (415 $\mu \mathrm{m})$ which exhibited the best performance for PEMFC [14], and a silicone gasket (thickness: $250 \mu \mathrm{m}$, hardness: $50^{\circ}$ shore A), as sealant, was chosen to match the compressed thickness of GDL after the process of hot pressing in the unit cell combination.

\section{B. Membrane Electrode Assembly Fabrication}

There are several methods to coat catalyst ink on the surface of a membrane or GDL, such as ultrasonic-sprayed, air-sprayed, brush-coated, and ink-transferred from PTFE sheet. In the study, air-sprayed method was used to achieve a high quality of MEAs. Moreover, the technique of the gas diffusion electrodes (GDEs) was used in this study because the fabrication process is simpler and time saving than the process of catalyst coated membranes (CCMs).

The catalyst ink was prepared by using $50 \mathrm{wt} \%$ of $P t / C$ instead of $20 \mathrm{wt} \%$ which most journals were used [15]. The two main reasons are: first, $20 \mathrm{wt} \% \mathrm{Pt} / \mathrm{C}$ is difficult to well-dispersed owing to our expected Pt loading, $0.4 \mathrm{mg} / \mathrm{cm}^{2}$. The catalyst ink would need to be diluted by isopropyl alcohol or other solvents; second, to achieve the Pt loading, spraying $20 \mathrm{wt} \% \mathrm{Pt} / \mathrm{C}$ catalyst ink takes more time than that of using $50 \mathrm{wt} \% \mathrm{Pt} / \mathrm{C}$. Here we only report the optimal combinations among these components, thus the $P t$ loading would not be our point in this study. The combination presented here is able of being applied to any concentration of the Pt loading, Catalyst inks were prepared by mixing the 
commercial $50 \quad \mathrm{wt} \% \quad \mathrm{Pt} / \mathrm{C}$, Nafion solution (5 wt\%) ultrasonically ( $45 \mathrm{kHz}$ ultrasonic bath, $200 \mathrm{~W}$ max ultrasonic power, $30 \mathrm{~min}$ ) with appropriate amount of isopropyl alcohol, and a few deionized water. Deionized water needs to be added first to moisturize the $50 \mathrm{wt} \% \mathrm{Pt} / \mathrm{C}$ which would react and burn when contact to Nafion solution or isopropyl alcohol if it is dry. The ratio of $50 \mathrm{wt} \% \mathrm{Pt} / \mathrm{C}$ to Nafion was typically $25 \%$ to $75 \%$ by weight. Before spraying, the GDLs were put on a stainless steel coated chromium plate and then a mask with a designed open area was cut in the center on the top of the GDLs. The open area was as the same as the active area for air-spraying the catalyst ink. The chromium coated stainless steel plate and the GDLs were heated up at approximate $90^{\circ} \mathrm{C}$ to vaporize the unnecessary solvents. The catalyst inks were air-sprayed onto at the GDLs at certain catalyst loading of $0.4 \mathrm{mg} / \mathrm{cm}^{2}$ as GDEs. The last step of MEAs fabrication was prepared by hot-pressed at $140^{\circ} \mathrm{C}$ for $120 \mathrm{~s}$ under a pressure of $2.0 \mathrm{Mpa}$.

\section{Testing}

In the study, the composite flow field plates with the serpentine and straight channels machined were used as shown in Fig. 1. On one hand, the composite flow field plates can extend the fueling time inside the channels to enhance the efficiency. On the other hand, water in the cathode side could be drained out easily. The oxygen gas can flow in to react with the catalyst. The active area of the composite flow field plate is $5.6 \mathrm{~cm} \times 5.6 \mathrm{~cm}$. The four combinations of flow field channels, gas diffusion layers, and catalyst layers are listed in Table I in details.

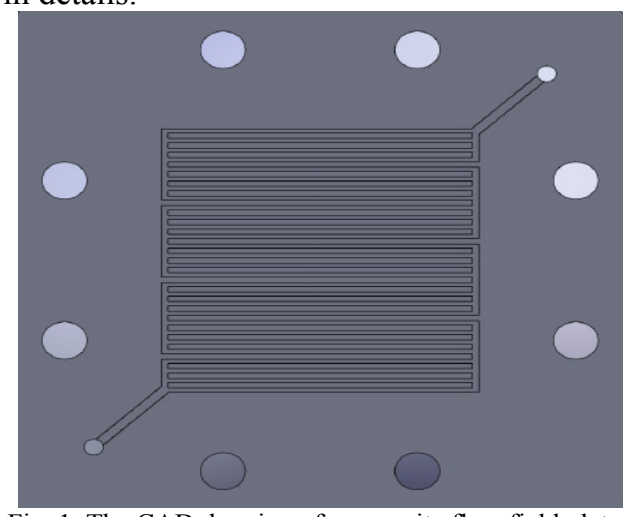

Fig. 1. The CAD drawing of composite flow field plate.

Four MEAs were assembled in the reference unit cell and set up on the commercial fuel cell test station. The proton exchange membrane fuel cell tests were all operated at $70^{\circ} \mathrm{C}$ and $100 \%$ relative humidity with ambient pressure on anode and cathode sides. The fuels were given $\mathrm{H}_{2}$ and $\mathrm{O}_{2}$ (1.5 and 2.0 stoichiometries) respectively. All polarization curves were measured until the current of each MEA was stable at constant voltage $(0.6 \mathrm{~V})$ activation.

\section{Performance of Replicate Samples}

To distinguish systematic patterns from a chance or random variation, we randomly chose 4 MEAs from 25 samples at a platinum loading of $0.4 \mathrm{mg} / \mathrm{cm}^{2}$ to testify the uniformity of our process and air spraying skill [16]. The areas of flow field channels, gas diffusion layers, and catalyst layers are all the same $(5.6 \mathrm{~cm} \times 5.6 \mathrm{~cm})$. Fig. 2 shows the polarization curves of four MEAs coated with GDEs method. The peak power densities are $0.989,0.993,0.987$, and 0.967 $\mathrm{W} / \mathrm{cm}^{2}$ operated at $65^{\circ} \mathrm{C}$ and $100 \%$ relative humidity with $\mathrm{H}_{2}$ and $\mathrm{O}_{2}$ fueling, means that the uniformity of each MEA is within $3 \%$.

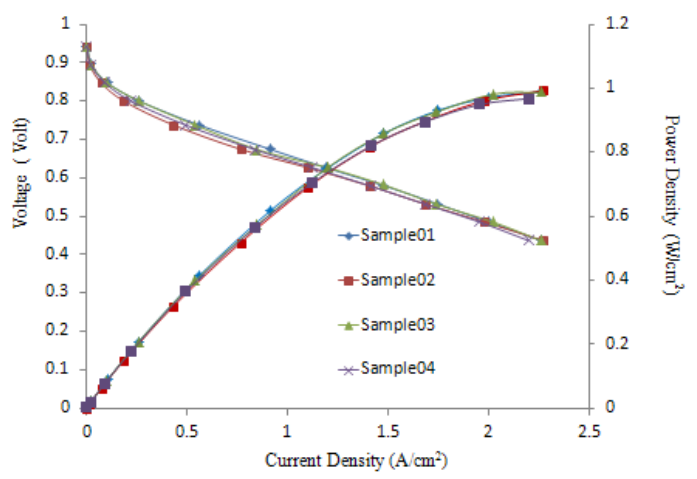

Fig. 2. Polarization and power density curves of 4 random MEAs coated with GDEs method at a platinum loading: $0.4 \mathrm{mg} \mathrm{cm}^{-2}$ at the anode and cathode. [16]

TABLE I: FOUR DETAILED COMBINATIONS (UNIT: CM $\times$ CM)
\begin{tabular}{|l|l|l|l|}
\hline & Flow field channels & Gas diffusion layers & Catalyst layers \\
\hline A & $5.6 \times 5.6$ & $5 \times 5$ & $5 \times 5$ \\
\hline B & $5.6 \times 5.6$ & $6 \times 6$ & $6 \times 6$ \\
\hline C & $5.6 \times 5.6$ & $5.6 \times 5.6$ & $5.6 \times 5.6$ \\
\hline D & $5.6 \times 5.6$ & $6 \times 6$ & $5 \times 5$ \\
\hline
\end{tabular}

\section{E. The Performance of the Four Combinations}

The polarization and power density curves of the four combinations were shown in Fig. 3. The detailed analysis and explanation for each combination were discussed in the following section.

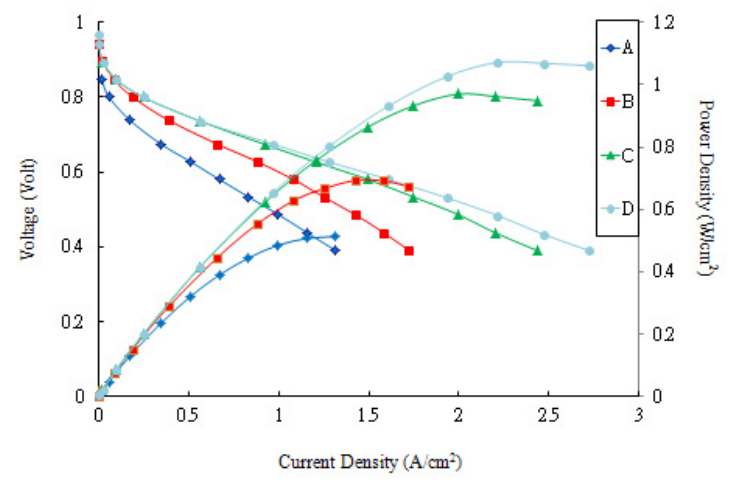

Fig. 3. Polarization and power density curves. the peak power density of the optimal combination was $1.07 \mathrm{~W} / \mathrm{cm}^{2}$ at $0.48 \mathrm{~V}$ for combination $\mathrm{D}$. for the worst combination (A), the peak power density was $0.51 \mathrm{~W} / \mathrm{cm}^{2}$ at $0.39 \mathrm{~V}$.

\section{F. Flow Field Channels: Gas diffusion layers: Catalyst Layers $=5.6 \times 5.6: 5 \times 5: 5 \times 5(\mathrm{~cm} \times \mathrm{cm})$}

In this combination, the area of gas diffusion layers and catalyst layers are smaller than that of flow field channels. While assembling, there is an approximate $2 \mathrm{~mm}$ gap between the gas diffusion layer and the silicon gasket because of handiwork. Hydrogen is highly active. During the test, hydrogen was supplied from the lower inlet. However, hydrogen didn't follow the flow field channels which we designed for gas flow to extend the fueling time in the unit cell. It flew out quickly from the lower inlet to the higher outlet via the gap as shown in Fig. 4. The shorter time of the 
fuel gas staying inside the channels provided the lower electrochemical performance of the cell. The peak power density of the combination $\mathrm{A}$ is $0.51 \mathrm{~W} / \mathrm{cm}^{2}$ at the voltage of $0.39 \mathrm{~V}$.

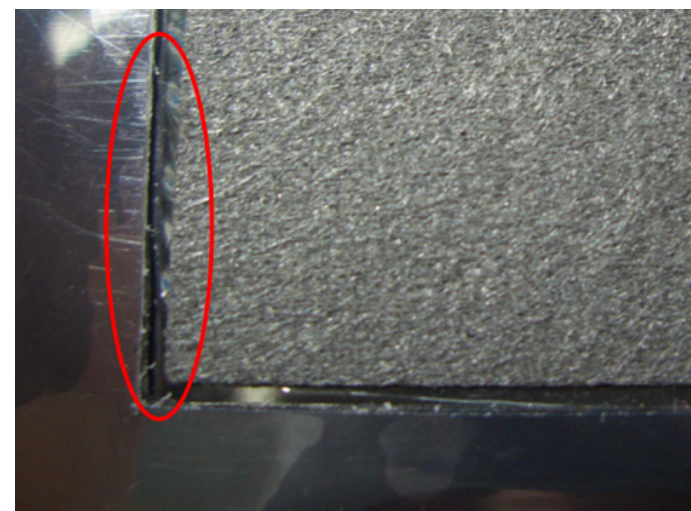

Fig. 4. There is an approximate $2 \mathrm{~mm}$ gap between the gas diffusion layer and the silicon gasket. It's a reasonable error while assembling by hand.

G. Flow Field Channels: Gas Diffusion Layers: Catalyst Layers $=5.6 \times 5.6: 6 \times 6: 6 \times 6(\mathrm{~cm} \times \mathrm{cm})$

In combination $\mathrm{B}$, the area of gas diffusion layers and catalyst layers are bigger than that of flow field channels. Even though that hydrogen couldn't flow out via the gap, the performance was not the optimal because of the catalyst waste. The total current/power is higher than that of others. However, the catalyst at the edge of the flow field channels cannot react with hydrogen/oxygen well. In this case, the current/power density is smaller than that of the total current/power is similar because of the bigger active area. The peak power density of the combination B is $0.69 \mathrm{~W} / \mathrm{cm}^{2}$ at the voltage of $0.48 \mathrm{~V}$

\section{H. Flow Field Channel: Gas Diffusion Layers: Catalyst Layers $=5.6 \times 5.6: 5.6 \times 5.6: 5.6 \times 5.6(\mathrm{~cm} \times \mathrm{cm})$}

In theory, the performance of the same areas of the three layers should be the most efficient. However, an issue should be discussed. The accuracy of the assembly is difficult in the combination. If the gas diffusion layer cannot just cover the flow field channels to prevent from the hydrogen leakage, the performance will be as low as the combination A. Once the MEA and the flow field channels are well-assembled, the performance would be extremely enhanced. In the combination $\mathrm{C}$, the peak power density is $0.97 \mathrm{~W} / \mathrm{cm}^{2}$ at the voltage of $0.48 \mathrm{~V}$.

\section{Flow field channels: Gas diffusion layers: Catalyst layers $=5.6 \times 5.6: 6 \times 6: 5 \times 5(\mathrm{~cm} \times \mathrm{cm})$}

The optimal combination of the three layers combination is D. The hydrogen/oxygen can react completely with the catalyst layers through the gas diffusion layers and the flow field channels while the areas of the catalyst layers are smaller than that of the flow field channels and the gas diffusion layers. Before using, the gas diffusion layers were immersed in the PTFE solution and became hydrophobic after heat treatment. The central area of the gas diffusion layers was hydrophilic because of the catalyst layers contained Nafion. However, at the edge of the gas diffusion layers, without the catalyst layers, was still hydrophobic. At the cathode side, the generated water was removed effectively. In the case, even though the volume of the cell is bigger than others' and the use of the component is a little waste because of the bigger area of the gas diffusion layers, the efficiency of the fuels and the performance are the highest. Moreover, it's more convenient for assembly. In combination $\mathrm{D}$, the peak power density is $1.07 \mathrm{~W} / \mathrm{cm}^{2}$ at the voltage of $0.48 \mathrm{~V}$.

\section{CONCLUSIONS}

In this paper, we reported four combinations of flow field channels, gas diffusion layers, and catalyst layers. In the beginning, we introduced that using $50 \mathrm{wt} \% \mathrm{Pt} / \mathrm{C}$ is easier to disperse than $20 \mathrm{wt} \% \mathrm{Pt} / \mathrm{C}$. To obtain the expected Pt loading, spraying $50 \mathrm{wt} \% \mathrm{Pt} / \mathrm{C}$ catalyst ink can reduce the process time. In further, we have shown the polarization and power density curves of randomly chose 4 MEAs from 25 samples to prove the uniformity of the process of MEAs fabrication and the composite flow field plates with serpentine and straight channels machined for the electrochemical test. From the four combinations, we have discussed that the area of the gas diffusion layers must be bigger than that of the flow field channels to prevent from hydrogen leakage or the fuel would be wasted to cause the bad performance. It's acceptable to get better performance if a little material or volume has to be wasted. The optimal combination is that the area of the gas diffusion layers are bigger than that of the flow field channels and the area of the flow field channels are bigger than that of the catalyst layers as well. Through the investigation of the different combinations, the highest performance with the optimal combination $\left(1.07 \mathrm{~W} / \mathrm{cm}^{2}\right)$ is two times higher than that of the worst combination $\left(0.51 \mathrm{~W} / \mathrm{cm}^{2}\right)$.

\section{ACKNOWLEDGMENT}

This work has been financially supported by National Science Council (NSC), R.O.C. Taiwan.

\section{REFERENCES}

[1] J. Larminie and A. Dicks, Fuel Cell Systems Explained, 2nd ed., U.K.: Wiley, 2003

[2] P. Costamanga and S. Srinivasan, "Quantum jumps in the PEMFC science and technology from the 1960s to the year 2000: Part I Fundamental scientific aspects," J. Power Sources, vol. 102, pp 242-252, Dec. 2001.

[3] P. Costamanga and S. Srinivasan, "Quantum jumps in the PEMFC science and technology from the 1960s to the year 2000: Part II Engineering, technology development and application aspects," $J$ Power Sources, vol. 102, pp. 253-269, Dec. 2001

[4] C. S. Kong, D. Y. Kim, H. K. Lee, Y. G. Shul, and T. H. Lee, "Influence of pore-size distribution of diffusion layer on mass-transport problems of proton exchange membrane fuel cells," $J$. Power Sources, vol. 108, pp. 185-191, June 2002.

[5] J. J. Hwang, D. Y. Wang, N. C. Shih, D. Y. Lai, and C. K. Chen, "ScienceDirect.com - Journal of Power Sources - Development of fuel-cell-powered electric bicycle," J. Power Sources, vol. 133, pp. 223-228, June 2004.

[6] R. Beneito, J. Vilaplana, and S. Gisbert, "Electric toy vehicle powered by a PEMFC stack," Int. J. Hydrogen Energy, vol. 32, pp. 1554-1558, July 2007.

[7] M. Oszcipok, M. Zedda, J. Hesselmann, M. Huppmann, M. Wodrich, M. Junghardt, and C. Hebling, "Portable proton exchange membrane fuel-cell systems for outdoor applications," J. Power Sources, vol. 157, pp. 666-673, July 2006.

[8] A. Bayrakceken, S. Erkan, L. Turker, and I. Eroglu, "Effects of membrane electrode assembly components on proton exchange membrane fuel cell performance," Int. J. Hydrogen Energy, vol. 33, pp. 165-170, 2007.

[9] A. P. V. Leal, F. R. Palomo, F. Barragan, C. Garcia, and J. J. Brey, "Design of control systems for portable PEM fuel cells," J. Power Sources, vol. 169, pp. 194-197, June 2007. 
[10] M. S. Wilson, "Membrane catalyst layer for fuel cells," U. S. Patent No. 5211 984, May 18, 1993.

[11] S. Y. Cha and W. M. Lee, "Performance of proton exchange membrane fuel cell electrodes prepared by direct deposition of ultrathin platinum on the membrane surface," J. Electrochem. Soc., vol. 146, pp. 4055-4060, Nov. 1999.

[12] B. Millington, V. Whipple, and B. G. Pollet, "A novel method for preparing proton exchange membrane fuel cell electrodes by the ultrasonic-spray technique," J. Power Sources, vol. 196, pp. 8500-8508, Oct. 2011.

[13] K. Tuber, M. Zobel, H. Schmidt, and C. Hebling, "A polymer electrolyte membrane fuel cell system for powering portable computers," J. Power Sources, vol. 122, pp. 1-8, July 2003.

[14] H. K. Lee, J. I. Kim, J. H. Park, and T. H. Lee, "A study on self-humidifying PEMFC using Pt-Zr-Nafion composite membrane," Electrochimica Acta, vol. 50, pp. 761-768, 2004.

[15] H. Tian, Z. Y. Shi, J. S. Shi, and Z. Q. Shan, "Preparation of water management layer and effects of its composition on performance of PEMFCs," Energy Conversion and Management, vol. 49, pp. 1500-1505, June 2008.

[16] C. Y. Liu and C. C. Sung, "A review of the performance and analysis of proton exchange membrane fuel cell membrane electrode assemblies," J. Power Sources, vol. 220, pp. 348-353, Dec. 2012.

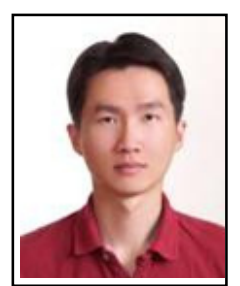

Chao-Yang Liu was born in Taichung, Taiwan, in 1980. He received his B.S. degree in electrical engineering from Yuan Ze University, Taiwan, in 2002, and then received his M.S. degree in electrical engineering from University of California, Riverside, USA, in 2007 and studying Ph.D. in Engineering Science and Ocean Engineering in National Taiwan University, Taiwan, from 2010 . This is the $3^{\text {rd }}$ year of his Ph.D. study. In 2007, he joined the General Optics Corp., Taiwan, as a chemical engineer, and in 2009 became a researcher in Tension Energy Inc. Since 2010, he changed to Advanced Lithium Electrochemistry Co., Ltd. as a deputy engineer. His current research interests include PEM fuel cell, water electrolysis of hydrogen production and ozone water generation, lithium ion battery fabrication and tests. Mr. Liu has published three SCI journals and attended an International conference of the $62^{\text {nd }}$ Canadian Chemical Engineering Conference held in Vancouver, Canada. He's also one of inventors of five patents, four in Taiwan and one in USA.

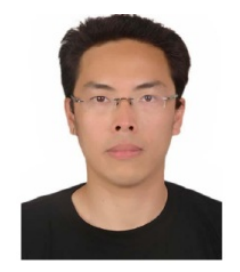

Lung-Hao Hu was born on $26^{\text {th }}$ Sept in 1977 , in Taipei, Taiwan. Dr. Hu obtained his B.S at Tatung University, Taiwan in 2000 and then received his M.S. and $\mathrm{PhD}$ in Mechanical Engineering at University of Colorado Boulder, U,S. in 2005 and 2010 , respectively. His research interests include the energy materials and devices, especially in the fields of hydrogen / lithium energy and electrochemical analysis of battery, fuel cell and supercapacitor. Duing his education in the U.S. he was doing the research at the University of Trento, Italy as an exchange scholar for two years (2007 2009). After he graduated, he continuously stayed at the University of Colorado Boulder to be a Postdoctoral Fellow to work on the anode material of lithium ion battery, collaborating with A123. After his return to Taiwan, he was working in a Battery Material and Transportation company as a Battery RD Engineer. Currently he is a Postdoctoral Fellow at IAMS, Academica Sinica, Taipei, Taiwan,. His publications include four scientific journal papers and one special topic book published. One of his proceeding papers is publishing in Nature series journal paper.

His researches were focusing on the hydrogen generation via metal hydrides with the certain functionalized PDCs catalyst and the anode material of lithium ion battery using SiOC (Silicon oxycarbide). His current research is focusing on the 2D materials such as graphene and MoSx for lithium ion battery. Dr. Hu is a membership of Member of American Nano Society (ANS) and the reviewer of the International Journal of Hydrogene Energy, Energy and Environmental Sciences, Journal of Materials Chemistry, Chem. Comm., and Journal of Power sources.

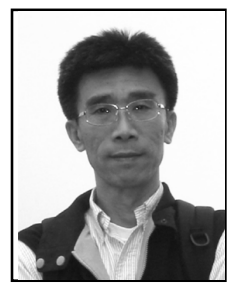

Chia-Chi Sung was born in Kaohsiung, Taiwan in 1958. He received the bachelor degree from Department of Naval Architecture, National Taiwan University (NTU) in 1981, and the Ph. D. degree from Department of Engineering Science and Mechanics, Pennsylvania State University in 1991. In1986 - 1991 at Penn State, Professor Sung worked on the topics of active torsional vibration control using shear mode piezo ceramic tubes.

As a professor in the Department of Engineering Science and Ocean Engineering, National Taiwan University, his research has been focused on structural acoustics and development of ultrasonic devices since 1991. Since the energy issue is getting more and more important part of his research has been focused on the development of fuel cell in the past 5 years. 